\title{
PODE A DELIBERAÇÃO QUALIFICAR POLÍTICAS PÚBLICAS PARA O MEIO RURAL? UMA ANÁLISE DA PARTICIPAÇÃO DE SUJEITOS RURAIS NA POLÍTICA PÚBLICA DE MECANIZAÇÃO AGRÍCOLA EM VIÇOSA- $M{ }^{1}$.
}

\section{CAN THE DELIBERATION QUALIFY POLICIES FOR RURAL AREAS? AN ANALYSIS OF THE PARTICIPATION OF RURAL SUBJECTS IN THE AGRICULTURAL MECHANIZATION OF PUBLIC POLICY IN VIÇOSA-MG}

\author{
Anna Cláudia Campos e Santos \\ Universidade Federal de Viçosa - Viçosa - MG - Brasil \\ Rennan Lanna Martins Mafra \\ Universidade Federal de Viçosa - Viçosa - MG - Brasil
}

\begin{abstract}
Resumo: Este artigo objetiva investigar o uso de mecanismos deliberativos democráticos junto a políticas públicas marcadas pela participação de sujeitos rurais. Como horizonte empírico investigativo, foi tomada a Política Pública de Mecanização Agrícola implementada e avaliada no Município de Viçosa-MG, a partir de processos deliberativos engendrados em seu Conselho Municipal de Desenvolvimento Rural Sustentável - CMDRS. Sendo assim, questiona-se se pode a deliberação pública qualificar as políticas públicas para o meio rural a partir de processos formais de participação política, marcados pelo diálogo público e sistemático entre sujeitos rurais e instituições. A fundamentação teórica é composta por abordagens acerca das noções de democracia deliberativa e avaliação de processos deliberativos formais. A abordagem principal foi inspirada na teoria de Archon Fung (2006), que indica três
\end{abstract}

\footnotetext{
1 Este artigo é parte dos resultados do projeto de pesquisa "Fortalecimento Cívico e Aprimoramento da Participação de Comunidades Rurais junto ao Conselho Municipal de Desenvolvimento Rural Sustentável de Viçosa/MG", financiado pela Fundação de Amparo à Pesquisa do Estado de Minas Gerais (Fapemig) e pelo Ministério Público do Estado de Minas Gerais, como parte do "Programa Cidade e Alteridade: Convivência Multicultural e Justiça Urbana".
} 
grandes critérios para avaliar a participação: seleção participante; modos de comunicação e decisão; autoridade e poder. No que se refere aos métodos, foram realizadas entrevistas e observação não participante na arena do CMDRS de ViçosaMG. Os principais resultados apontam que existem processos deliberativos embrionários deflagrados por sujeitos rurais na implementação e avaliação da política pública destacada, pois há concreta consideração por parte do executivo pelas falas e reclamações dos mesmos. No entanto, não há o desenvolvimento público de preferências, não levando ao debate e à criação de pautas em conjunto, nem à ampliação das controvérsias públicas na arena do CMDRS no que se refere às experiências dos sujeitos rurais.

Palavras-chave: Deliberação. Política pública. Participação. Meio rural.

Abstract: This article aims to investigate the use of deliberative democratic mechanisms with public policies marked by the participation of rural subjects. As investigative empirical horizon was taken Agricultural Mechanization of Public Policy implemented and evaluated in Viçosa-MG, from deliberative processes engendered in Municipal Council for Sustainable Rural Development. Thus, it wonders whether the public deliberation can qualify public policy for rural areas from formal processes of political participation, marked by the public and systematic dialogue between rural individuals and institutions. The theoretical framework consists of approaches about deliberative democracy notions and evaluation of formal decision-making processes. The main approach was inspired by the theory of Archon Fung (2006) that indicates three major criteria to evaluate participation: participant selection; communication and decision; authority and power. As regards the methods, were interviews and nonparticipant observation in the arena of CMDRS, Viçosa-MG. The main results show that there are embryonic deliberative processes triggered by rural subjects in the implementation and evaluation of public policy highlighted as there are concrete consideration by the executive by speeches and complaints from them. However, there is not the public development of preferences, not leading to debate and creating agendas together, or expansion of public controversy in CMDRS arena with regard to the experiences of rural subjects.

Keywords: Deliberation. Policy. Participation. Rural.

\section{Introdução}

As teorias recentes pautadas pela abordagem da democracia deliberativa apontam a importância da existência de espaços participativos formais como arenas indispensáveis para que os governantes possam realizar ações públicas em diálogo com as expectativas dos diretamente afetados. Inevitável, portanto, uma influência desta abordagem no debate sobre políticas públicas (MARQUES, 2009; COELHO E NOBRE, 2004), uma vez que tais teorias insinuam que política pública não é apenas o que o Estado faz ou deixa 
de fazer (DYE, 1987), mas, sim, o que o Estado faz ou deixa de fazer considerando os diretamente afetados, a partir de um espaço de participação, no qual demandas podem ser identificadas de um modo deliberativo. Assim, essas mesmas teorias problematizam a criação de políticas públicas de caráter democrático (MARQUES, 2009), compreendendo a participação como gesto central à produção de legitimidade política e de justiça em contextos complexos e pluralistas (FARIA, 2013).

Políticas públicas voltadas para o meio rural também demonstram fazer coro a esse movimento. Segundo Schneider et al (2009), o ano de 1996 representa um marco legal, por meio do qual o Estado reconhece a agricultura familiar como uma categoria social e política. Um dos aspectos definidores das políticas públicas para o meio rural a partir de tal reconhecimento refere-se ao forte traço participativo, a partir da criação de desenhos colegiados para tomada de decisão conjunta entre sujeitos rurais e instituições.

Este é o caso, por exemplo, da criação, em 1999, do Conselho Nacional de Desenvolvimento Rural Sustentável, âmbito deliberativo formal voltado à discussão do Programa Nacional de Fortalecimento da Agricultura Familiar - Pronaf2. Tal conselho incentivou a instituição de desenhos deliberativos semelhantes no âmbito municipal, os CMDRSs. Assim, Schneider, Cazella \& Mattei (2009, p 42) apontam que o surgimento dos CMDRSs tem como objetivo básico envolver as comunidades rurais e os agricultores familiares na criação, implementação, gestão e fiscalização das políticas públicas. Na visão dos autores, tal prerrogativa se dá a partir "da necessidade crescente do Estado de promover formas de gestão descentralizadas que promovam, ao mesmo tempo, maior eficiência no uso dos recursos e ampliação dos mecanismos de acesso da população, levando a uma maior democratização".3

\footnotetext{
2 O Pronaf é um programa que visa ao fortalecimento da agricultura familiar, por meio de apoios técnico e financeiro, para que se promova o desenvolvimento rural sustentável. Como objetivos gerais, pode-se citar o fortalecimento da capacidade produtiva da agricultura familiar; a contribuição para geração de emprego e renda nas áreas consideradas rurais e a melhoria na qualidade de vida do agricultor familiar.

3 Através da Resolução $n^{\circ} 28$ de 28 de fevereiro de 2002, a importância dos Conselhos foi reforçada, com a criação, a partir do Pronaf Infraestrutura dos Conselhos Municipais de Desenvolvimento Rural Sustentável.
} 
No caso do Município de Viçosa/MG ${ }^{4}$, verifica-se esta tendência de criação de espaços deliberativos na gestão de políticas públicas para o meio rural, a partir da constituição do CMDRS, em 2004. O conselho se apresenta como um órgão gestor de caráter consultivo e deliberativo, vinculado ao poder público municipal. Dessa forma, tomando como base a legislação que regulamenta o CMDRS (Lei $n^{0} 2.081 / 2010$ e Lei 2.137/2011), é possível identificar três principais âmbitos de atuação do Conselho: (1) fomento à participação e à discussão da política pública de desenvolvimento rural sustentável do município, assegurando a participação de órgãos do poder público e de representantes de entidades da sociedade civil e de organizações paragovernamental afins à temática, quanto particularmente de comunidades (organizadas formalmente ou não) e de entidades representativas dos agricultores familiares e de trabalhadores assalariados rurais; (2) estímulo à articulação intersetorial $e$ à organização da sociedade civil; e (3) incentivo à representação e à manifestação da cultura local. Com tais âmbitos, fica explícita a proposta do CMDRS de produzir políticas públicas de desenvolvimento rural em Viçosa tanto de modo sustentável - fazendo coro às discussões contemporâneas que aproximam as políticas de desenvolvimento à temática da sustentabilidade - quanto de modo dialogado e participativo - produzindo-se enquanto prática institucional pautada por recentes experiências democráticas, que apostam na participação dos cidadãos como caminho relevante para produção de políticas públicas mais justas e legítimas (HABERMAS, 1997, 2006; MANSBRIDGE, 1999; DRYZEK, 2004; BENHABIB, 1996; COELHO E NOBRE, 2004; MARQUES, 2009).

Dentre as inúmeras propostas discutidas na arena do CMDRS, chamou atenção o fato de que a política pública de Mecanização Agrícola do município tenha sido, nas suas edições de 2013 e 2014, implementada e avaliada na arena formal deste Conselho, lançando mão, para isso, de processos público-reflexivos com a participação de conselheiros das comunidades rurais que têm assento no CMDRS e que são diretamente afetados por tal política.

\footnotetext{
4 Localizado no Estado de Minas Gerais, na Zona da Mata Mineira, o Município de Viçosa possui população de aproximadamente 72 mil habitantes, sendo aproximadamente $93 \%$ da população residente na área urbana e $7 \%$ da população residente na área rural (IBGE, 2010).
} 
Um fato instigante foi que, nos anos de 2013 e 2014, o poder executivo municipal abriu espaço para discussão no CMDRS às formas de implementação da política pública de Mecanização Agrícola, e, posteriormente, realizou um processo de avaliação, de modo dialogado no mesmo conselho, acerca do modo como tal política foi implementada. Sendo assim, causou curiosidade $o$ fato de a participação dos sujeitos rurais no CMDRS ter sido tomada como um possível parâmetro não apenas de efetividade da aplicação da política pública, mas também de legitimidade pública. Nesse sentido, tomando como horizonte empírico investigativo os processos participativos engendrados junto à política pública de Mecanização Agrícola em Viçosa, o objetivo principal deste artigo é questionar se pode a deliberação qualificar políticas públicas para o meio rural a partir de uma análise da participação dos sujeitos rurais com base na política escolhida.

Sabe-se que, de modo geral, não são recentes as investigações sobre participação e deliberação no âmbito dos conselhos gestores de políticas públicas 5 . Entretanto, no caso da relação entre desenhos institucionais participativos e meio rural, a partir das modificações institucionais no âmbito das políticas de agricultura familiar, existe ainda um considerável campo de investigação a ser desvendado. Numa busca por trabalhos recentes, voltados a abordar tal cenário, encontrouse alguns estudos que abordam a questão da participação de sujeitos rurais em processos decisórios, tendo em vista o surgimento dos CMDRSs (MOURA, 2007; SCHNEIDER et. al, 2009; MUCCI e MAFRA, 2015; 2016). Em tais estudos, identificou-se avanços na ampliação da agenda, apesar da identificação de problemas na qualidade da participação (FREITAS et al., 2012). Em outros trabalhos, há evidências de baixa participação dos agricultores em tais processos (MEDEIROS E BORGES, 2007) ou ainda de alta rotatividade dos representantes dos agricultores no âmbito dos conselhos (BISPO JUNIOR e SAMPAIO, 2008) em cenários marcados por fortes diferenças entre representantes da sociedade civil e do poder público, situação esta que indica uma correlação desigual de forças dentro de espaços de deliberação. Assim, algumas visões apresentam os CMDRSs como espaços consultivos com baixo potencial

\footnotetext{
${ }^{5}$ Existem clássicos trabalhos sobre conselhos de políticas públicas, tais como os de Tatagiba (2002; 2005) e Cunha (2004),
} 
de força de influência dos sujeitos em suas deliberações (OLIVAL et al., 2007). Identificou-se também trabalhos que apresentam a descrença de movimentos sociais sobre a efetividade de esferas participativas (BISPO JUNIOR e SAMPAIO, 2008; SEVERO E ROS, 2012).

Nesse sentido, fica evidente que a participação torna-se objeto de interesse de inúmeros trabalhos. Entretanto, falta, em grande parte dos mesmos, uma problematização dos aspectos participativos à luz de noções da democracia deliberativa ${ }^{6}$, abordagem esta que tem se mostrado como produtiva à análise de políticas públicas em contextos democráticos. De tal sorte, ao problematizar os processos participativos produzidos entre agricultores familiares e instituições locais, este artigo se ancora nas noções deliberacionistas como enquadramentos conceituais capazes de trazer à tona importantes aspectos que devem ser considerados na análise de recentes desenhos institucionais, inspiradores a várias políticas públicas de desenvolvimento rural.

Dessa forma, a escolha metodológica deste artigo se deu pela abordagem qualitativa: ao lançar foco em questões não explícitas, não repetitivas e, muitas vezes, não objetiváveis (MINAYO, 2010), tal abordagem tornou-se útil à compreensão de aspectos atinentes à deliberação pública, nos contextos participativos acolhedores de instituições e sujeitos rurais. De modo mais específico, dados primários foram levantados por meio da realização de: i) entrevistas - a partir de roteiro semiestruturado - aplicado com conselheiros titulares ou suplentes, ou ainda com representantes informais, vinculados a oito comunidades rurais representadas na arena do CMDRS7 e uma entrevista

\footnotetext{
${ }^{6}$ Apenas os trabalhos de Mucci e Mafra $(2015 ; 2016)$ bebem da mesma fonte teórica comum deste artigo e se filiam a discussões empreendidas no Copráticas - Grupo de Pesquisa em Comunicação, Democracia e Práticas Sociais da Universidade Federal de Viçosa (UFV), grupo este detalhado em nota seguinte.

7 O critério de seleção de quais comunidades seriam escolhidas para entrevista deu-se com a consulta das atas das reuniões do CMDRS de 2013 e 2014, buscando encontrar quais comunidades estavam presentes nas discussões da Política de Mecanização Agrícola. Assim, encontramos onze comunidades presentes, porém foi possível realizar apenas entrevistas com oito delas, uma vez que houve a recusa por parte de um conselheiro e grande dificuldade de comunicação com os demais, impedindo a realização das entrevistas até a finalização deste trabalho. Assim, as entrevistas ficaram orientadas pela seguinte forma: 4 entrevistas foram realizadas com representantes titulares; 1 com representante suplente; 1 com representante titular e com representante suplente; 1 com representante informal, sendo que este é o
} 
com o poder executivo representado pelo Secretário de Desenvolvimento Rural e Agropecuária do município; e ii) observação não participante das reuniões mensais do CMDRS ${ }^{8}$. As entrevistas foram realizadas entre os meses de setembro, outubro e novembro do ano de 2014 e a observação não participante aconteceu entre os meses agosto e julho dos anos de 2013 e 2014. Também é válido ressaltar que utiliza-se alguns dados secundários a partir de uma base coletiva de levantamentos promovida pelo Grupo de Pesquisa em Comunicação, Democracia e Práticas Sociais (Copráticas), no âmbito de um projeto de pesquisa maior, ao qual esse trabalho se filia ${ }^{9}$.

Para dar conta de organizar as questões ora propostas, as discussões empreendidas por este artigo se organizam em algumas partes. A seção $A$ qualificação democrática de políticas públicas recentes: a aposta na deliberação pública pretende discutir como a abordagem conceitual da democracia deliberativa compreende a instituição de mecanismos discursivos e dialógicos como aposta para a

morador da comunidade que acompanha todas as reuniões; 1 com representante titular, representante suplente e representante informal; totalizando oito entrevistas, com a participação de 5 mulheres e 6 homens.

8 O CMDRS de Viçosa se reúne sempre na primeira segunda-feira de cada mês. As reuniões têm início às $12 \mathrm{~h} 45$ com término estimado até às 15 horas. Elas aconteciam, entre os anos de 2011 e 2014, comumente no espaço da Universidade Federal de Viçosa (UFV), numa edificação cedida à Empresa de Assistência Técnica e Extensão Rual do Estado de Minas Gerais (EMATER). Desde o ano de 2015, as reuniões têm acontecido também na UFV, agora no espaço da Seção Sindical dos Docentes da UFV (ASPUV).

9 O Copráticas é um grupo de pesquisa da Universidade Federal de Viçosa (UFV) que promove investigações em torno de quatro linhas de pesquisa: comunicação, democracia e periferia; comunicação e experiência; comunicação e processos cooperativos; e dispositivos dialógicos e contextos organizacionais. Dentre outras atividades, o grupo desenvolveu, entre os anos de 2013 a 2016, o projeto "Fortalecimento Cívico e Aprimoramento da Participação de Comunidades Rurais junto ao Conselho Municipal de Desenvolvimento Rural Sustentável de Viçosa/MG", conforme explicitado na primeira nota de rodapé. Em tal projeto, os pesquisadores constituíram uma base comum de dados a partir do desenvolvimento de um formulário para observação não participante, utilizado para investigação de 36 (trinta e seis) reuniões do CMDRS de Viçosa. Tal instrumento de coleta permitiu a observação das falas dos conselheiros, os temas em pauta, as discussões que influenciavam decisões, os temas não deliberados, dentre outros aspectos. 
qualificação de políticas públicas em contextos sociais complexos e pluralistas. Em seguida, a seção $O$ cubo da democracia de Fung: a oferta de categorias e modalidades analíticas para compreensão da deliberação em processos participativos formais busca apresentar o modelo analítico desenvolvido pelo pesquisador Archon Fung (2006) como proposta à interpretação de desenhos institucionais participativos - como os das políticas públicas - , nos quais a deliberação pública torna-se central. Adiante, a seção $A$ pesquisa da participação na Política Pública de Mecanização Agrícola de Viçosa/MG busca utilizar três categorias propostas por Fung (2006) - seleção participante; modos de comunicação e decisão; autoridade e poder - para discussão dos dados coletados na pesquisa supracitada, a fim de se compreender se os processos deliberativos ocorridos no âmbito do CMDRS apresentam indícios de qualificação a políticas públicas para o meio rural. Por fim, a seção Considerações Finais apresenta as principais conclusões do artigo, a partir da síntese de alguns aspectos e da identificação de possíveis lacunas a serem respondidas em estudos futuros.

\section{A qualificação democrática de políticas públicas recentes: a aposta na deliberação pública}

Nos cenários sociais contemporâneos, marcados pela complexidade das relações entre sujeitos e instituições, bem como por demandas coletivas de grupos plurais, a teoria democrática recente tem buscado responder, dentre outros aspectos, como é possível a instituição de gestos de governabilidade, pautados pela legitimidade e pela justiça das decisões públicas (Habermas, 1997). Sendo assim, a aposta na noção de deliberação pública tem suscitado o surgimento de um vasto debate, marcado por inúmeros conceitos e nuances, com a finalidade de encontrar respostas à qualificação democrática na relação entre Estado, instituições e cidadãos. Este contexto interlocutivo se estende ao campo investigativo das políticas públicas.

Ainda que tal debate seja permeado de peculiaridades, algo parece ser central em inúmeras vertentes deliberacionistas: a visada na constituição de mecanismos argumentativos, instauradores de amplos processos público-reflexivos, responsáveis pela consideração de pontos de vista plurais e pela construção de acordos possíveis, como resultado de um escrutínio público inclusivo e ampliado. Dessa forma, 
superando a fundamentação democrática convencional do mecanismo do voto, a noção de democracia deliberativa pretende considerar os aspectos das diferenças e da hiperespecialização como balizadores possíveis a um modelo normativo capaz de dar conta das questões atinentes à legitimidade e à justiça. Nesse cenário, as reflexões do intelectual alemão Jürgen Habermas (1997) mostram-se nucleares, em torno das quais gravitam os elementos basilares que compõem a noção de deliberação pública.

Habermas (1997) busca, em sua teoria, encontrar formas para que, dado o contexto das sociedades complexas e pluralistas, haja o respeito às diferenças nos modos de pensar e viver. Isso pode ocorrer a partir da instauração de processos de deliberação, por meio dos quais questões podem ser discutidas a partir de processos de argumentação e, por esses termos, carregam potencial de serem tomadas como legítimas a partir da justificação das mesmas. Assim, a comunicação e, sobretudo, o poder comunicativo ganha ênfase na teoria de Habermas, pelo fato de ser o "poder" que resulta do procedimento deliberativo de discussão e deliberação. Ele ganha forma na esfera pública e geralmente é contraposto à esfera do poder político-administrativo (LUBENOW, 2010). Assim todo discurso defendido no âmbito de uma esfera pública deve se dar por meio de um agir comunicativo (que está baseado em uma forma de ação contrária a ação estratégica) e de uma razão comunicativa. Esta última baseia-se em princípios voltados ao entendimento mútuo e a um discurso pautado pela disposição de ouvir o que o outro deseja também colocar (OLIVEIRA, 2014).

Para Habermas (1997), a deliberação pública ocorre quando se baseia, dessa forma, numa espécie de ética do discurso (Marques, 2010). A ética do discurso tem sua base na ideia de solidariedade, em que o indivíduo deve se colocar no lugar do outro mesmo quando ele não for diretamente atingido pela questão colocada, tendo a partir daí a formação do indivíduo enquanto interlocutor capacitado, atuando junto a um espaço de criação de "fenômenos que constituem a aceitação discursiva de normas em contraposição à sua mera internalização" (HABERMAS, 2004 apud MARQUES, 2010, p 79). Para Habermas, é através da ética do discurso que todos os indivíduos são tidos como iguais, e por meio da qual todos possuem o mesmo direito de fala, possuindo assim as mesmas condições para elaborarem e defenderem 
seus argumentos. Destarte, para que, de fato, possam exercer essa capacidade de fala, é preciso que exerçam também sua autonomia política.

Ainda que tal noção esteja filiada a um amplo e complexo debate, em meio ao qual existem inúmeras críticas, peculiaridades e novos desenvolvimentos teóricos, a teoria do discurso habermasiano se apresenta como uma espécie de epicentro teórico, ao propor um procedimento que possibilite a deliberação e a tomada de decisões aos governos contemporâneos, calcado no intercâmbio argumentativo racional e na supremacia de uma força moral prática, que emerge a partir da fusão de horizontes e perspectivas diferentes em torno de uma proposta reflexiva comum, construída pela comunicação na esfera pública. De forma ideal, o debate seria, por esses termos, uma espécie de propulsor ao avanço das regras democráticas, em termos de fundamentação e legitimação das mesmas (FARIA, 2000).

Dessa maneira, Habermas (1997) formula um projeto de institucionalização que se orienta pela ação recíproca, presente tanto em esferas informais do mundo da vida 10 quanto em esferas formais de tomadas de decisão, ambas conectadas por processos comunicativos engendrados em esferas públicas de discussão política, capazes de direcionarem aos governos uma força comunicativa voltada a influenciar os processos de administração pública, dotando-os de legitimidade. (Habermas, 1997). Quanto a isso, Lubenow (2010) ressalta que a concepção habermasiana está relacionada, sobretudo, com o desejo da ampliação da participação dos indivíduos nos processos de deliberação e decisão e no fomento de uma cultura política democrática. $O$ caráter procedimental garante formalmente a participação de forma igualitária em processos de formação discursiva da opinião e da vontade, voltado a estabelecer, dessa forma, um procedimento legítimo de normatização.

Ao focar no procedimento, Habermas (1997) está interessado em analisar de que modo se dá a formação dos argumentos, e não necessariamente dá destaque ao conteúdo dos mesmos. Assim, seu projeto é construído de forma bastante rígida, uma vez que a

\footnotetext{
10 Para Habermas, o mundo da vida é um conjunto de percepções que possibilita aos indivíduos interpretarem questões relacionadas a vários aspectos da vida, como família, religião, ciência, entre outros.;
} 
deliberação só é alcançada se os argumentos estiverem baseados em características tais como racionalidade, não-coerção, reciprocidade e universalidade, vinculadas à sua noção de ética do discurso. James Bohman (2009), é um dos autores considerados deliberacionistas, mas que modifica sua visão quanto à deliberação estar baseada nos parâmetros da ética do discurso e no modo procedimental construído por Habermas. Para Bohman (2009) a deliberação pública adquire um caráter substancial, ou seja, a preocupação se dá no sentido de observar qual o conteúdo dos argumentos (e não unicamente o modo como estes são formados). Diferentemente de Habermas (1997), Bohman (2009) aposta na deliberação como uma espécie de diálogo que se estabelece entre duas ou mais pessoas. Nas palavras do autor:

\footnotetext{
em vez do pré-comentimento e do procedimentalismo, argumento a favor de uma abordagem da deliberação baseada no diálogo, pois é somente em diálogo com os outros falando com eles, respondendo a eles, e considerando seus pontos de vista - que as muitas e diversas capacidades para a deliberação são exercidas conjuntamente. O diálogo público é possível, mesmo com aqueles de quem discordamos e com aqueles que não estão literalmente presentes entre nós (BOHMAN, 2009, p 32).
}

Assim, para Bohman (2009), a deliberação pública ocorre por meio de uma ampla cooperação pública (FARIA, 2000):“a justificação não procedimentalista da deliberação pública está baseada na troca dialógica livre e inclusiva, na qual os interlocutores oferecem razões, recebem considerações e providenciam respostas uns aos outros" (BOHMAN, 2009, p 37). Para isso, faz-se necessário que (1) os indivíduos tenham acesso ao que tem sido discutido, em um tipo de exposição social dos fenômenos, intenções, planos e atualidades; e (2) para além deste conhecimento, a exposição das posições do conhecimento comum esteja relacionada às normas que regulam o diálogo e a negociação dos entendimentos em público (MAIA, 2008).

Assim, segundo Faria (2000, p 60), Bohman considera que os critérios deliberacionistas estão pautados na ideia de que os indivíduos que participam de um processo público-reflexivo reconhecem que podem contribuir e influenciar seus resultados - ou, nos termos do autor, podem cooperar na deliberação -, mesmo que discordem dos 
acordos sempre provisórios dos debates:. "como certos tipos de influência não são suficientes para induzir a cooperação, o diálogo deliberativo busca minimizar as influências não públicas e substituí-las pelas influências dos contribuidores no debate público (...)". Assim, é nesse sentido que o grupo ou ator envolvido coopera na deliberação, pois espera que sua visão seja incorporada ou pelo menos considerada na decisão.

Os cenários contemporâneos das políticas públicas brasileiras têm incorporado vários mecanismos deliberativos, tendo como justificativa a aposta na produção de decisões mais legítimas, das quais participariam instituições e sujeitos diretamente afetados por seus resultados. Quanto a isso, o pesquisador Archon Fung (2006) oferece uma concepção analítica voltada à compreensão da deliberação pública engendrada em processos participativos formais'1. Tal concepção, denominada de cubo da democracia, será discutida a seguir, uma vez que se mostrou bastante útil à análise dos mecanismos deliberativos envoltos à participação de sujeitos rurais na implementação e avaliação da Política Pública de Mecanização Agrícola em Viçosa/MG.

\section{O cubo da democracia de Fung: a oferta de categorias e modalidades analíticas para compreensão da deliberação em processos participativos formais}

Archon Fung (2006) empreende reflexões sobre como a participação pode se dar nos governos democráticos. Sendo assim, desenvolve três categorias analíticas que se tornam muito úteis à investigação dos processos de deliberação pública em âmbitos participativos formais: 1) seleção participante; 2) modos de comunicação e decisão; e 3) autoridade e poder. Cada categoria é

\footnotetext{
11 Quanto a isso, é válido apontar que Archon Fung (2006) não se apresenta como um autor deliberacionista. Entretanto, suas teorias calcadas no campo da adminsitração pública tangenciam os interesses do campo da ciência política, do direito, da comunicação e das ciências sociais. Por tal razão, há aproximações relevantes entre os interesses de Fung (2006) no estudo da participação em processos formais, e as reflexões sobre a democracia deliberativa. A título de exemplo, no livro "Participação e Deliberação:teoria democrática e experiências institucionais no Brasil contemporâneo", de Coelho e Nobre (2004), foi publicado um texto de Archon Fung junto a vários autores deliberacionistas.
} 
operacionalizada por Fung (2006) em determinadas modalidades, sendo estas as formas sugeridas pelo autor por meio das quais podese inferir sobre a qualidade das práticas participativas. Dito por outras palavras, cada categoria pode ser subdividida em modalidades, conforme se apresenta o quadro a seguir:

Quadro 1. A compreensão da deliberação pública em processos participativos formais: categorias e modalidades

\begin{tabular}{|c|c|c|c|}
\hline Categorias & Seleção participante & $\begin{array}{c}\text { Modos de } \\
\text { comunicação e } \\
\text { decisão }\end{array}$ & Autoridade e poder \\
\hline \multirow{8}{*}{$\begin{array}{c}\text { Modalidades } \\
\text { Vinculadas à cada } \\
\text { categorias }\end{array}$} & $\begin{array}{l}\text { administradores } \\
\text { especialistas } \\
\text { (mais exclusiva) }\end{array}$ & $\begin{array}{c}\text { apenas ouvir } \\
\text { (menos intensiva) }\end{array}$ & $\begin{array}{c}\text { busca de benefícios } \\
\text { pessoais } \\
\text { (menos autoridade) }\end{array}$ \\
\hline & $\begin{array}{c}\text { representantes } \\
\text { eleitos }\end{array}$ & $\begin{array}{c}\text { expressar } \\
\text { preferências }\end{array}$ & $\begin{array}{c}\text { influência } \\
\text { comunicativa }\end{array}$ \\
\hline & $\begin{array}{l}\text { intervenientes } \\
\text { profissionais }\end{array}$ & $\begin{array}{l}\text { desenvolver } \\
\text { preferências }\end{array}$ & $\begin{array}{c}\text { aconselhamento e } \\
\text { consulta }\end{array}$ \\
\hline & partes interessadas & agregar e barganhar & cogovernança \\
\hline & seleção aleatória & deliberar e negociar & \multirow{4}{*}{$\begin{array}{c}\text { autoridade direta } \\
\text { sobre as decisões } \\
\text { (mais autoridade) }\end{array}$} \\
\hline & $\begin{array}{c}\text { aberto, recrutamento } \\
\text { alvo }\end{array}$ & \multirow{3}{*}{$\begin{array}{c}\text { implantar técnica e } \\
\text { experiência } \\
\text { (mais intensiva) }\end{array}$} & \\
\hline & aberto, auto-seleção & & \\
\hline & $\begin{array}{c}\text { difusão na esfera } \\
\text { pública } \\
\text { (mais inclusiva) }\end{array}$ & & \\
\hline
\end{tabular}

Fonte: Adaptado de Fung (2006).

A primeira categoria, seleção participante, diz respeito a quem participa dos processos deliberativos formais: "alguns processos participativos são abertos a todos os que desejam se envolver, enquanto outros convidam apenas as partes interessadas da elite, como representantes de grupos de interesse" (FUNG, 2006, p 67, tradução nossa). Contém oito modalidades que descrevem possíveis papéis sociais implicados na seleção de participantes: administradores especialistas; representantes eleitos; intervenientes profissionais; partes interessadas; seleção aleatória; aberto, recrutamento alvo; aberto, autoseleção; e difusão na esfera pública. Assim, quanto mais próxima das primeiras modalidades apresentadas, a participação tende a ser mais exclusiva), e, por sua vez, quanto mais próxima das últimas modalidades, a participação tende a ser mais inclusiva. 
De modo mais específico, para Fung (2006), a participação tende a ser mais inclusiva quando é capaz de acolher um maior número de pessoas no processo de tomada de decisões. Assim, fica como desafio aos mecanismos participativos permitirem que todos aqueles que desejam, possam, participar. No entanto, inúmeras práticas participativas existentes tendem a ser mais exclusivas ao recrutarem, por exemplo, apenas administradores especialistas, representantes eleitos ou intervenientes profissionais Para o autor, a inclusão começa a se tornar mais significativa quando partes interessadas, dispostas a investir tempo e energia, são convocadas a tomar assento em espaços produtores de decisões, estas últimas que as afetam diretamente. Por esse raciocínio, a seleção aberta, seja por recrutamento alvo, seja por autosseleção, combinada com a difusão da participação na esfera pública, torna-se a modalidade que tende a ser mais inclusiva, na visão de Fung (2006).

A segunda categoria, modos de comunicação e decisão, diz respeito a como os participantes trocam as informações e como se dão as tomadas de decisões: "em muitas reuniões públicas, os participantes simplesmente recebem informações de oficiais que anunciam e explicam as políticas" (FUNG, 2006, p 67, tradução nossa), ocasiões nas quais raramente acontece um processo deliberativo, por meio do qual participantes podem modificar discursivamente suas opiniões ao longo de um processo público-reflexivo, pautado pelo intercâmbio de razões. Dessa forma, tal categoria é composta por seis modalidades, que expressam possíveis modos sobre os quais a comunicação acontece entre participantes, e decisões são encaminhadas como resultados da participação: apenas ouvir; expressar preferências; desenvolver preferências; agregar e barganhar; deliberar e negociar; e implantar técnica e experiência. Assim, quanto mais próxima das primeiras modalidades, a participação tende a ser menos intensiva e, por sua vez, quanto mais próxima das últimas modalidades, a participação tende a ser mais intensiva.

Quanto a isso, é válido apontar que há forte consideração dos processos deliberativos a partir da quarta modalidade elencada por Fung (2006): nesse caso, a participação tende a se delinear de forma mais complexa, a partir da qual a tomada de decisão se dá por meio da agregação e da negociação de preferências: "a característica de 'dar e 
receber' da negociação permite aos participantes encontrarem a melhor alternativa possível para avançar as preferências conjuntas que eles possuem" (FUNG, 2006, p 68, tradução nossa). Dessa forma, na quinta modalidade, deliberação e negociação, mecanismos deliberativos podem auxiliar no surgimento de um acordo "com princípios, na resolução de divergências persistentes e na descoberta de novas opções que melhor promovam o que os participam valorizam" FUNG, 2006 (p. 69, tradução nossa) ${ }^{12}$.

Por fim, a terceira categoria, autoridade e poder, visa a identificar se há ligação entre o que é discutido e a ação pública em si mesma. Tal categoria é composta por cinco modalidades e avalia a ligação entre o que os participantes dizem e o que as autoridades ou os próprios participantes fazem: busca de benefícios pessoais; influência comunicativa; aconselhamento e consulta; cogovernança; e autoridade direta sobre as decisões. Assim, quanto mais próxima das primeiras categorias, a participação tende a possuir menos autoridade e, por sua vez, quanto mais próxima das últimas categorias, tende a possuir mais autoridade.

Quanto a isso, é válido apontar que, na primeira modalidade, o participante tem pouca ou nenhuma expectativa de poder influenciar as decisões, uma vez que participa para obter benefícios pessoais. A partir da segunda modalidade, há influência comunicativa que possui autoridade sobre o Estado, de modo que, na terceira modalidade, uma espécie de assessoria e/ou consulta é formalizada, por meio da qual "fóruns participativos exercem influência sobre a autoridade pública" (FUNG, 2006, p 69, tradução nossa). A quarta modalidade já diz respeito ao poder direto exercido pela participação, em uma espécie de parceira cogovernamental, por meio da qual cidadãos podem se unir a funcionários públicos para realizar planos e estratégias de ação. $\mathrm{O}$ último nível descreve a participação com o poder de exercer autoridade direta sobre as decisões e os recursos públicos.

Dessa forma, seleção participante, modos de comunicação e decisão e autoridade e poder constituem, para Fung (2006), referências que

\footnotetext{
12 Aqui, é válido citar que, para Fung (2006), a sexta modalidade da categoria modos de comunicação e decisão restringe-se aos funcionários públicos, estes que devem, por meio de seus conhecimentos técnicos, tomarem as decisões indicadas por processos participativos anteriores. Assim, tal situação não envolve a participação de indivíduos, mas somente do Estado.
} 
indicam como qualquer mecanismo de decisão pública, pautado pela participação, pode ser identificado e qualificado. Para isso, Fung (2006) combina tais categorias num modelo de análise, ao qual chama de cubo da democracia, no qual "as variedades de mecanismos participativos podem ser localizadas e contrastadas" (p. 70, tradução nossa) e questões como legitimidade, justiça e eficácia podem ser aferidas. Sendo assim, tomando como inspiração as categorias de seleção participante, modos de comunicação e decisão e autoridade e poder, bem como suas respectivas modalidades, a próxima seção pretende analisar a Política Pública de Mecanização Agrícola do Município de Viçosa/MG, que contou com a participação de sujeitos rurais, nas edições de 2013 e 2014, nos momentos de sua implementação e avaliação, na arena deliberativa formal do CMDRS. O intuito principal, nesse sentido, é buscar compreender se os processos deliberativos ocorridos no CMDRS apresentam indícios de qualificação da participação de sujeitos rurais no âmbito de tal política pública.

\section{A pesquisa da participação na Política Pública da Mecanização Agrícola de Viçosa/MG}

Num breve rasante histórico, a Mecanização Agrícola teve início, em Viçosa/MG, em 1998 e, nesta época, tal política se constituía somente em subsídio oferecido pela Prefeitura Municipal, destinado aos agricultores, e constituído pela disponibilização de determinadas horas de uso de trator para auxiliar em momentos de plantio e/ou colheita. Nesse sentido, o subsídio do trator foi somente o embrião para a consolidação posterior de uma ação mais sofisticada, cujo benefício se constituía numa combinação entre ofertas de horas de trator juntamente com o compartilhamento de técnicas de plantio e produção. Por fim, com o surgimento de máquinas como a plantadeira e a colheitadeira, criou-se a Política de Mecanização Agrícola, constituída então pelo subsídio sistemático e organizado de trator, de plantadeira e de colheitadeira, bem como pelo compartilhamento de técnicas de plantio e de produção por parte de técnicos da Prefeitura Municipal de Viçosa.

Com o reconhecimento institucional da categoria "agricultor familiar", sobretudo a partir da criação do Pronaf, a Política tomou, como seu público-alvo, agricultores familiares situados em pequenas 
propriedades rurais, identificadas como estando abaixo de dez hectares. Para participar da política, o agricultor precisa se dirigir à Secretaria Municipal de Desenvolvimento Rural e Pecuária do município e apresentar documentação comprobatória 13, dentro de um prazo estipulado. Nas edições da Política acompanhadas nessa pesquisa, o período de implementação ocorreu entre os meses de março e setembro - sendo março e abril para cadastro das demandas, e maio a setembro para oferta dos subsídios previstos - e o período de avaliação aconteceu nos meses de outubro e novembro, tanto em 2013 quanto em 2014.

Dessa forma, o número de horas subsidiado objetiva auxiliar o agricultor familiar em seus trabalhos rotineiros ${ }^{14}$. Atualmente, a distribuição de horas de máquinas foi terceirizada, e é oferecida através de processo de licitação. A respeito do trabalho de orientação técnica, trata-se de um processo extensionista, nos termos do próprio Secretário Municipal de Desenvolvimento Rural e Pecuária, sobre o ato de se plantar com foco na produtividade, a partir do que os agentes da política chamam de "fazer as correções adequadas do solo". Além disso, segundo o Secretário, tem-se buscado estimular o agricultor a utilizar um plantio que seja o menos ambientalmente degradável possível, por meios de conversas e visitas direcionadas, nas quais são repassadas orientações e indicações de técnicas de plantio direto, tomadas como prioritárias ${ }^{15}$.

\footnotetext{
13 A documentação comprobatória refere-se à mesma definida pelo Pronaf para a identificação do agricultor familiar.

$14 \mathrm{Na}$ região de Viçosa, segundo a Secretaria de Desenvolvimento Rural e Pecuária, a produção agrícola prioritária constitui-se, sobretudo de milho e feijão.

15 O plantio direto é uma técnica de cultivo conservacionista em que o plantio é efetuado sem as etapas do preparo convencional da aração e da gradagem. Nessa técnica, é necessário manter o solo sempre coberto por plantas em desenvolvimento e por resíduos vegetais. Essa cobertura tem por finalidade proteger o solo do impacto direto das gotas de chuva, do escorrimento superficial e das erosões hídrica e eólica. Pode ser considerado como uma modalidade do cultivo mínimo, visto que o preparo do solo limita-se ao sulco de semeadura, procedendo-se à semeadura, à adubação e, eventualmente, à aplicação de herbicidas em uma única operação. (...) É entendido como um sistema com os seguintes fundamentos: redução das operações de preparo do solo; uso de herbicidas para o controle de plantas daninhas; formação e manutenção da cobertura morta; rotação de culturas; uso de semeadoras específicas. (EMBRAPA, BRASIL, 2014).
} 
Desde o surgimento da Mecanização Agrícola até o ano de 2012, o processo de agendamento do uso das máquinas e das orientações técnicas ficava a cargo somente da Prefeitura Municipal. Entretanto, após reclamações sobre mal atendimento, supostos privilégios no momento de oferta dos subsídios e problemas na comunicação entre a Prefeitura e os agricultores, a novidade foi que, nos anos de 2013 e 2014, a Secretaria Municipal de Desenvolvimento Rural e Pecuária encontrou no CMDRS um espaço deliberativo voltado à discussão sobre as formas de implementação da política. De modo mais específico, o modo como a política fora formulada ficou a cargo somente da Prefeitura. Entretanto, as formas de implementação e de posterior avaliação da Mecanização Agrícola passaram a ser deliberadas junto com representantes dos diretamente afetados pela política, ou seja, agricultores familiares, moradores de comunidades rurais do município.

Dessa forma, antes da implementação do subsídio da Mecanização, na edição de 2013, o Secretário foi ao CMDRS numa reunião e expôs as dificuldades encontradas aos Conselheiros. Pediu que os mesmos pudessem apresentar também problemas e que voltassem às suas comunidades para conversar com os outros agricultores acerca da Mecanização. Na reunião do mês seguinte, os conselheiros retornaram ao CMDRS e trouxeram propostas efetivas sobre a implementação - além de terem assumido, junto à Prefeitura, o papel de fiscalizadores e/ou de facilitadores, sobretudo durante as horas disponibilizadas para uso das máquinas nas comunidades rurais. Foi construída uma agenda de oferta dos subsídios nas comunidades, que foi disponibilizada pelos conselheiros aos agricultores de sua região de representação. Após o término das ações da Mecanização, o Secretário voltou novamente à arena do CMDRS para avaliar a implementação e buscar dados para fazer alterações que fossem necessárias para a próxima edição da política - gesto esse que foi acompanhado por pesquisadores do Copráticas entre os anos de 2013 e 2014.

Nesse sentido, com o intuito de avaliar se a participação desses sujeitos rurais em torno dos processos deliberativos envoltos à Mecanização Agrícola foi capaz de qualificar a própria política no âmbito do meio rural de Viçosa. Utilizar-se-á as três categorias propostas por Fung (2006) - seleção participante, modos de 
comunicação e decisão e autoridade e poder -, para apresentar os resultados da pesquisa qualitativa realizada a partir de entrevistas com os conselheiros do CMDRS e com o Secretário Municipal de Desenvolvimento Rural e Pecuária.

\section{Seleção participante}

De acordo com os dados coletados, no que diz respeito à seleção dos participantes no momento de criação da Política de Mecanização, os conselheiros do CMDRS não foram consultados. Obviamente, quando foi criada essa política, o Conselho não existia. Entretanto, o Secretário reconhece a importância do Conselho e da participação dos agricultores para a qualificação das ações da Mecanização:

(...) O motivo principal [por não ter sido consultado] é porque o Conselho não existia... tá? o Conselho veio a existir em $2004 . .$. a criação quando eu ainda estava aqui na Agricultura... uma iniciativa que começou o próprio movimento dentro do Estado a nível federal... de criação de conselhos do meio rural onde pudesse tá tendo proximidade com o homem do campo... o Conselho... ele é uma ferramenta, né?... pra gente... é... da gente poder ter ali, é... próximo da gente, todas as informações de cada comunidade... nesse período que a gente entrou agora... é... posso falar claramente que a gente alterou parte da mecanização... a gente entendia que passou um... o município em si passou por uma transformação em $2013 \ldots$ pelo fato seguinte... quando se criou a mecanização agrícola... trabalhava como eu te falei... uma questão mais braçal... você não tinha plantadeira, você não tinha colheitadeira... você não trabalhava por exemplo, é... produtividade no campo... então os trabalhos feitos eram... a mecanização foi elaborada pra um modelo, daquela época. hoje nós vivemos um outro modelo de produtor rural... então no Conselho, desse período que a gente tá agora de 2013 pra cá... a gente reformulou a mecanização.... ampliando o número de horas... ouvindo o pessoal do Conselho... e vendo também a necessidade de campo... que... a gente viu a necessidade, levou pro Conselho... o Conselho foi favorável às nossas alterações... (Secretário Municipal de Desenvolvimento Rural e Pecuária).

Dessa forma, nos termos de Fung (2006), pode-se considerar que o momento de criação da Mecanização Agrícola contou somente com a participação de administradores especialistas, ou seja, funcionários da 
própria Prefeitura e agentes políticos, uma vez que a política não foi discutida e deliberada em contextos participativos ampliados. Já no o momento da implementação, houve participação de administradores especialistas - o próprio Secretário, funcionários da Secretaria e da Empresa Mineira de Assistência Técnica e Extensão Rural - EMATER, com assento no CMDRS - e de representantes eleitos - sujeitos rurais, conselheiros das comunidades rurais de Viçosa. No caso dos momentos de avaliação da política, acontecidos na própria arena do CMRDS, além dos administradores especialistas e dos representantes eleitos, a ocasião contou com uma equipe de professores e pesquisadores da Universidade Federal de Viçosa - UFV (instituição com assento formal no CMDRS), os quais, nos termos de Fung (2006), podem ser enquadrados como intervenientes profissionais . Quanto a isso, é válido apontar que, durante a avaliação, a equipe da UFV trouxe ponderações que se referiam muito mais aos processos deliberativos ocorridos no âmbito do Conselho do que a aspectos a serem aprimorados nas comunidades rurais - de modo que tais aspectos ficaram a cargo dos representantes eleitos, os sujeitos rurais.

Entretanto, um dado curioso necessita ser ressaltado: os representantes eleitos tentaram instaurar processos de discussão acerca da implementação/avaliação da política em suas comunidades rurais. Assim, muniam-se de informações advindas dos diretamente afetados pela política - agricultores familiares beneficiários da Mecanização Agrícola. Nos termos de Fung (2006), tais agricultores moradores das comunidades rurais podem ser classificados na modalidade partes interessadas. Assim, ainda que os mesmos não tivessem participado das reuniões do CMDRS, pode-se considerar que as partes interessadas foram inseridas no processo participativo implicado na Política Pública no momento em que os conselheiros foram agentes importantes na discussão local acerca da implementação da Mecanização.

Dessa forma, do ponto de vista de Fung (2006), ainda que a criação da política tenha tendido a ser mais exclusiva, seus modos de implementação e de avaliação, em 2013 e 2014, apresentaram-se como tendencialmente mais inclusivos. Obviamente, não participaram do processo de implementação e de avaliação grupos sociais outros que pudessem questionar, por exemplo, a própria existência da Mecanização em cenários contemporâneos marcados por práticas 
agroecológicas e de desenvolvimento sustentável - gesto esse que poderia atribuir, à seleção participante, um grau de inclusividade bem maior.

Modos de comunicação e decisão

Analisando os dados por meio do o segundo critério de Fung (2006) modos de comunicação e decisão, pode-se inferir que os conselheiros participaram, antes de tudo, como sujeitos capazes de expressar e desenvolver suas preferências.

Entretanto, por meio das entrevistas, foi possível notar que há dificuldades no que se refere às capacidades de agregar e barganhar, bem como as de deliberar e negociar. Dessa forma, falar com frequência nas reuniões, apesar de indicar o desenvolvimento de preferências, não pressupõe capacidade de influenciar decisões acerca da política, como aponta um dos entrevistados: "a gente fala sim... o que precisa melhorar, só que a gente sabe que não pode colocar mais horas... porque... se não num tem condições né?"(Entrevistado 2, Sujeito Rural).

Dessa forma, Fung (2006) aponta que expressar e/ou desenvolver preferências é gesto que não implica necessariamente na construção de uma visão coletiva que produz uma decisão, fruto de uma deliberação refletida e intercambiada por razões. Como aponta o próprio autor, em alguns processos participativos formais "as autoridades comprometemse a não mais do que receber o testemunho de participantes e considerando seus pontos de vista em suas próprias deliberações posteriores" (FUNG, 2006, p 68, tradução nossa).

O acompanhamento das reuniões mensais do CMDRS e a entrevista feita com o Secretário de Agricultura corroboram a assertiva de Fung (2006). As falas dos conselheiros são levadas em consideração pelo Secretario - o que não deixa de ser um ponto muito positivo, como se apresentam os depoimentos a seguir:

não... porque as pessoas já encontra com ele... já fala... entendeu? ele busca informação... ele liga... ele pergunta... cê entendeu? então assim... ele busca informação. ele mantem contato... ele liga pra mim e pergunta "e aí, como que tá?"... liga pra outras pessoas da comunidade... ele... outra coisa... você liga pra ele... chamou e não atende, tranquilo, com pouco ele te retorna. então às vezes ele tá em reunião, cê ligou pra ele 
e tal, chamou chamou... ou ele manda uma mensagem... (Entrevistado 2, Sujeito Rural).

(...) troquei opinião com ele [o secretário] primeiro lá [na reunião do Conselho]... e ele aceitou... só que foi feito muito pouco... mas isso já vem debatendo desde... dos... do primeiro é... é... (...) secretário de agricultura que apareceu... nunca me aceitou... (Entrevistado 4, Sujeito Rural).

dá pra conversar em qualquer lugar que encontrar com ele... tem jeito de você conversar com ele... num tem... você não precisa de ficar... marcando... igual tem lugar que você tem que ficar marcando... agora, (...) cê encontra com ele na rua... cê encontrou com ele no escritório... qualquer lugar que ocê estiver com ele cê pode estar conversando com ele... ele dá esse espaço pra gente em qualquer lugar que ele tá... (Entrevistado 8, Sujeito Rural).

O próprio Secretário, quando questionado sobre o que o CMDRS representava para o funcionamento da Política de Mecanização Agrícola, afirmou

(...) é... ferramenta hoje indispensável no meu ponto de vista. pra que a gente possa de fato tá fazendo um trabalho. é a ferramenta que a gente tem hoje de planejamento, de elaboração do nosso trabalho é o Conselho (Secretário Municipal de Desenvolvimento Rural e Pecuária)).

No caso da Mecanização Agrícola, a observação nas reuniões sobre os debates para a escala do uso do trator em cada comunidade reafirmam a importância que o Conselho adquiriu para a Secretaria Municipal de Desenvolvimento Rural e Pecuária no processo de implementação da Política. Entretanto, é também inegável que há uma ausência de mecanismos de deliberação que permitem aos conselheiros não apenas desenvolverem novos pontos de vista, mas também construírem coletivamente uma opinião que seja capaz de influenciar as decisões e de fazê-los descobrir interesses comuns. Assim, ainda que o CMDRS cumpra um papel relevante junto ao poder executivo municipal, no intuito de tornar públicas realidades vivenciadas pelos sujeitos, os processos participativos se apresentam como tendencialmente menos intensivos, no que se refere aos modos de comunicação e de decisão, perdendo em potencialidades de influenciação junto ao 
encaminhamento concreto de decisões para além dos limites que são permitidos pelos agentes institucionais.

Autoridade e poder

Por fim, tomando o terceiro critério proposto por Fung (2006), autoridade e poder, é possível considerar que a ligação entre o que é discutido nas reuniões, a partir de um intercâmbio racional públicoreflexivo e as decisões tomadas, apresenta-se por meio de uma relação de aconselhamento e consulta. Para Fung (2006), nesse tipo de relação estabelecida, os participantes conseguem exercer certa influência sobre a autoridade pública, que se compromete em receber a opinião dos participantes. Mas, o compromisso de recebimento das opiniões não implica, necessariamente, num processo de cogovernança. Assim, a autoridade da participação no CMDRS, no que se refere à Política de Mecanização Agrícola, apresenta limites no que diz respeito ao processo de uma governança compartilhada. Inclusive, na fala do Secretário, o mesmo demonstra se comprometer com as opiniões que emergem no âmbito do CMDRS, mas também busca utilizar outros mecanismos de contato com as comunidades que acontecem fora da arena deliberativa do CMDRS

o Conselho ele é uma ferramenta de trabalho pra gente. uma ferramenta indispensável hoje... pra tá podendo atender o meio rural com qualidade pelo menos razoável, num vou te dizer $100 \% .$. uma qualidade razoável... (...) a gente tenta... simplesmente o que a gente tem em mãos, o que a gente tem disponível, aplicar com maior eficiência possível pra poder tá atendendo o Conselho. o Conselho em partes, a comunidade né?... que a gente fala Conselho é... mas é a comunidade... (...)na verdade a gente tem a prática de estar sempre na comunidade... a gente sempre tá... por exemplo, tô ouvindo de uma comunidade agora... sempre a gente tá em todas as comunidades... obviamente a gente não consegue estar é... cem por cento no município durante um período, mas sempre a gente tá em prática, (...) em contato com o pessoal na comunidade... que é onde que a gente ouve muitos problemas... (...) o conselheiro em si, ele acaba não conseguindo representar todos... então esse... contato diário na comunidade... é importante a 
gente tá sempre indo e... tá colhendo as informações do produtor no campo (Secretário Municipal de Desenvolvimento Rural e Pecuária).

Sendo assim, sem desconsiderar a importância de um órgão governamental estabelecer contato direto com os sujeitos e com as instituições que, por sua atuação, mostram-se como diretamente afetados, o dado anterior evidencia que a arena deliberativa do CMDRS não é o único espaço utilizado para a gestão da implementação da Política de Mecanização Agrícola. Em última análise, tal evidência indica um enfraquecimento da autoridade implicada nos processos participativos do CMDRS, diminuindo possibilidades de fortalecimento público do Conselho como arena agregadora de encaminhamentos argumentativos. De tal sorte, alguns sujeitos rurais podem preferir o contato direto com o Secretário do que com o representante eleito de sua comunidade para a discussão de questões sobre a Mecanização.

No entanto, vislumbrar a participação do CMDRS na modalidade aconselhamento e consulta é também reconhecer que tal arena não se torna desprovida de autoridade e poder, ainda que os mesmos não sejam capazes de instituir uma governança compartilhada. Assim, ao analisarmos os motivos que fizeram os conselheiros das comunidades rurais participarem do CMDRS e consequentemente, das discussões sobre a implementação e a avaliação da Política de Mecanização Agrícola, chegamos a duas principais evidências 16: (1) alguns deles participaram para obter benefícios pessoais ou para cumprir um senso de obrigação cívica; mas (2) grande parte dos entrevistados se dedicou a participar e a se envolver na implementação e na avaliação da Mecanização Agrícola, no âmbito do CMDRS, para fazer jus ao papel de representantes eleitos de suas comunidades, estando dispostos a instaurarem processos deliberativos, pautados pelo intercâmbio público de razões:

[me envolvo] mais pela comunidade... não utilizo porque... eu não sou meeiro... aliás, sou meeiro, mas... por causa de eu não... assim... ter um contrato de parceria... não ter assim...

\footnotetext{
16 Importante esclarecer que em algumas das entrevistas estas inferências não são encontradas de modo explícito, em algumas delas não encontramos sequer resposta para esta questão. Chegamos a esta conclusão tomando como base o maior número de respostas encontradas.
} 
um... um cartão de produtor pra mim movimentar... entendeu? por isso que a partir desse ano, eu num mexi com mecanização agrícola. mas até o ano passado eu mexi. (Entrevistado 5, Sujeito Rural)

[quando perguntado se usufrui da Política de Mecanização] ... não. lá é tudo particular. lá não tem nenhuma... lá quando vai... é... cortar terra, qualquer coisa, a gente paga particular... porque não pelo fato dos... da prefeitura. mas pelo... meu companheiro que eu tinha... que num gostava de mexer com isso. (...) [é] pela comunidade mesmo... (Entrevistado 7, Sujeito Rural)

Nesse sentido, alguns conselheiros também afirmaram que, são tidos como pontes entre as comunidades e o Conselho, sendo procurados para conversarem e receberem encaminhamentos a serem expostos na arena deliberativa do CMDRS:

Entrevistador: você me falou que o pessoal da sua comunidade... eles utilizam a mecanização agrícola... eles levam muitas reclamações até você? (...) levam informações até você... seja do lado positivo ou negativo?

Levam... a maioria... noventa... mais de noventa por cento... dos produtores... (Entrevistado 1, Sujeito Rural)

Entrevistador: sempre tá te procurando?...

Entrevistado 1: sempre procura... e sempre utiliza... da mecanização agrícola... (Entrevistado 1, Sujeito Rural)

ntrevistador: se eles veem você como... assim... um meio de contato... se você mantem essa relação com eles de sempre conversar sobre a mecanização agrícola?... se você troca ideia com o pessoal da comunidade?...

Não sempre... às vezes alguém procura pra conversar, mas nem sempre... né? as pessoas procuram mais quando tem problema né? quando num tem... tá calado... (Entrevistado 2, Sujeito Rural)

Entrevistador: mas te procuram pra falar da mecanização?

Procuram e falam 'ah, a plantadeira esse ano não foi legal...' entendeu? o pessoal fala... (Entrevistado 2, Sujeito Rural)

De tal sorte, no que se refere à categoria autoridade e poder, proposta por Fung (2006), é possível considerar que, ainda que o intercâmbio argumentativo sobre a Mecanização Agrícola, realizado na arena do CMDRS, não se invista de uma autoridade capaz de instituir uma gestão compartilhada da implementação e avaliação da Política, a deliberação 
pública, de algum modo, qualifica a participação, tornando-a, de certa forma, capaz de produzir aconselhamentos e consultas. Se tais aconselhamentos serão utilizados para modificar a Mecanização, tratase de decisão cuja autoridade se encontra nas mãos do Executivo Municipal.

\section{Considerações Finais}

Com a proposta de compreender se pode a deliberação qualificar políticas públicas para o meio rural, esse artigo buscou analisar os processos participativos empreendidos na arena do CMDRS de Viçosa, no que se refere à implementação e à avaliação da Política Pública de Mecanização Agrícola instituída no Município. Para isso, lançou mão de referências conceituais da democracia deliberativa e utilizou as categorias proposta por Archon Fung (2006) para problematizar a participação nos processos formais. Com relação a isso, é possível chegar a algumas conclusões acerca da pergunta principal que intitula esse trabalho. A deliberação realmente apresenta o potencial de qualificar as políticas públicas para o meio rural. No entanto, tomando a realidade problematizada da Política de Mecanização Agrícola, é possível considerar que: (1) a deliberação torna-se efetiva, na medida em que a seleção participante mostra-se mais inclusiva, aberta a todos que desejarem tomar parte nos processos público-reflexivos; (2) os modos de comunicação e de decisão se apresentam como efetivos na medida em que os mesmos forem capazes de oferecer possibilidades de negociação junto às instituições tomadoras de decisão - para além de um processo não menos relevante de desenvolvimento conjunto de preferências; e (3) as arenas deliberativas tornam-se fortalecidas no momento em que se tornam abertas à ampla participação, sendo capazes de produzir um processo de governança compartilhada, no qual instituições e sujeitos assumem papeis diferentes, voltados, entretanto, para uma consideração mútua no que se refere a reflexões e a um intercâmbio público de razões.

Por fim, compreender as potencialidades de qualificação de políticas públicas para o meio rural, a partir da deliberação pública engendrada em contextos participativos, é gesto que solicita uma compreensão do contexto social mais amplo em que sujeitos rurais e 
instituições sociais interagem. Nesse sentido, uma compreensão mais efetiva acerca da relação entre deliberação pública e aspectos como legitimidade, justiça e eficácia das políticas - temática esta que merece ser abordada em estudos futuros - torna-se possível na medida em que a problematização de aspectos culturais e socioeconômicos do contexto de interação entre sujeitos e instituições puderem ser acionados, a partir de métodos e escolhas conceituais que ampliem o horizonte teórico-investigativo ora proposto..

\section{REFERÊNCIAS}

AGÊNCIA EMBRAPA DE FORMAÇÃO TECNOLÓGICA, Plantio Direto. Disponível em http:<//www.agencia.cnptia.embrapa.br/gestor/milho/arvore/CONTAG 01_72_59200523355.html>. Acesso em: 06 de dezembro de 2014.

AVRITZER, Leonardo. Teoria democrática e deliberação pública. In: Lua Nova, $n^{\circ} 49,2000$.

O Orçamento Participativo: As experiências de Porto Alegre e Belo Horizonte. In: DAGNINO, E. (org.). Sociedade civil e espaços públicos no Brasil. São Paulo: Paz e Terra, 2002.

BENHABIB, Seyla. Toward a deliberative model of democratic legitimacy. In: BOHMAN, J. e REIGH, W (orgs). Deliberative democracy.. (ed.) Democracy and difference: contesting the boundaries of the political. Princeton: Princeton University Press, P. 67-94, 1996.

BISPO JUNIOR, J.P; SAMPAIO, J.J.C. Participação social em saúde em áreas rurais do nordeste do Brasil. Rev. Panam. Salud. Publica. 23(6): 403-09, 2008.

BOHMAN, James. O que é deliberação pública? Uma abordagem dialógica. In: MARQUES, A. (orgs.) A deliberação pública, e suas dimensões sociais, políticas e comunicativas. Belo Horizonte: Autêntica, pp 31-84, 2009. 
CAVALCANTE, Alberto R. A racionalidade comunicativa de Jurgen Habermas. In: Educação e Filosofia. V. 15, nº 29, pp. 225-257, 2001.

COELHO, Vera Schattan P; NOBRE, Marcos. Participação e deliberação: teoria democrática e experiências institucionais no Brasil contemporâneo. (Orgs.). São Paulo: Ed. 34, 2004. 368p.

CUNHA, E. S. M. Aprofundando a democracia: o potencial dos Conselhos de Políticas e Orçamentos Participativos. Belo Horizonte. 2004. Dissertação (Mestrado) - Departamento de Ciência Política, Faculdade de Filosofia e Ciências Humanas, Universidade Federal de Minas Gerais, 2004.

DRYZEK, J. S. Legitimidade e economia na democracia deliberativa. In: COELHO, V. P. S. e NOBRE, M. (Org.) Participação e deliberação - teoria democrática e experiências institucionais no Brasil contemporâneo. São Paulo: Editora 34, p.21-41, 2004.

FARIA, Cláudia, F. Democracia deliberativa: Habermas, Cohen e Bohman. In: Lua Nova, ${ }^{\circ}$ 49, p. 47-68, 2000.

- Democracia deliberativa e justiça. In: Dimensões políticas da justiça. (Orgs.) AVRITZER, L; BIGNOTTO N; FILGUEIRAS, F; GUIMARÃES, J. \& STARLING, H. Civilização Brasileira, Rio de Janeiro, 2013.

O que há de radical na teoria democrática contemporânea análise do debate entre ativistas e deliberativos. In: Revista Brasileira de Ciências Sociais, Vol. 25 n 73 junho/2010.

FREITAS, A. F. de; FREITAS, A. F. de. e DIAS, M. M. O colegiado de desenvolvimento territorial e a gestão social de políticas públicas: o caso do Território Serra do Brigadeiro, Minas Gerais. In: Rev. Adm. Pública - Rio de Janeiro 46(5):1201-223, set./out. 2012.

FUNG, Archon. Varieties of participation in complex governance. In: Public Administration Review, ed esp., p. 66-75, 2006. 
HABERMAS, Jürgen. Pensamento pós-metafísico: estudos filosóficos. Rio de Janeiro: Tempo Brasileiro, 1990.

- Três modelos normativos de democracia. In: Lua Nova. São Paulo, n.36, p. 39-53, 1995.

Política Deliberativa - um conceito procedimental de democracia. In: _-_-_.. Direito e Democracia. Rio de Janeiro: Tempo Brasileiro, p. 9$56,1997$.

O papel da sociedade civil e da esfera pública política. In:

Direito e Democracia. Rio de Janeiro: Tempo Brasileiro, 1997. pp 57121.

A Inclusão do Outro: estudos de teoria política. 1 a Ed. São Paulo: Edições Loyola, 2002.

HESPANHOL, Rosangela, Ap., de M. Mudança de concepção das políticas públicas para o campo brasileiro: O Programa de Aquisição de Alimentos (PAA). In: Scripta Nova, Revista Electrónica de Geografía y Ciencias Sociales, Universidad de Barcelona. Vol. XII, núm. 270 (79). Agosto, 2008 [Nueva serie de Geo Crítica. Cuadernos Críticos de Geografía Humana].

IBGE, Censo Demográfico. 2010. Disponível em: $<$ http://www.cidades.ibge.gov.br/xtras/temas.php?lang=\&codmun=31 7130 \&idtema $=1$ \&search $=$ minas - gerais $\mid$ vicosa $\mid$ censo-demografico2010:-sinopse->. Acesso em set. 2016.

LUBENOW, Jorge, A. Esfera Pública e Democracia Deliberativa em Habermas: Modelo teórico e discursos críticos. In: Kriterion, Belo Horizonte, $\mathrm{n}^{\circ} 121$, p. 227-258. Junho, 2010. 
MAIA, Rousiley C. M. Visibilidade midiática e deliberação pública. In: Comunicação e democracia. (Orgs.) GOMES, Wilson. \& MAIA, Rousiley C. M. São Paulo, Paulus, pp. 165-171, 2008.

MANSBRIDGE, Jane. Everyday Talk in Deliberative System. In: MACEDO, Stephen (ed.). Deliberative Politics: essays on democracy and disagreement. Oxfor: Oxford University Press, 1999.

MARQUES, Ângela C. S. A ética do discurso e a formação do sujeito político em Habermas. In: Cadernos da Escola do Legislativo, Volume 5, número 23, janeiro a junho de 2013.

Relações entre comunicação, estética e política: tensões entre as abordagens de Habermas e Rancière. In: Revista Compolítica, n. 2, vol. 2, ed. setembro-outubro, ano 2011. Rio de Janeiro: Compolítica, 2011.

(org). A deliberação pública e suas dimensões sociais, políticas e comunicativas. Belo Horizonte: Autêntica, 2009.

MARQUES, Francisco Jamil. O problema da participação política no modelo deliberativo de democracia. In: Revista Sociologia e Política. Curitiba, v. 20, n. 41, p. 21-35, fev. 2012.

MEDEIROS, J. P. de. e BORGES, D. F. Participação cidadã no planejamento das ações da Emater-RN. In: Rev. Adm. Pública Rio de Janeiro 41(1):6381, Jan./Fev. 2007.

MINAYO, Maria Cecília de Souza (org.). Pesquisa social: teoria, método e criatividade. 29 ed. Petrópolis, RJ: Vozes, 2010.

MOURA, J. T. V. de. Os Conselhos Municipais de Desenvolvimento Rural (CMDRS) e a construção democrática: esfera pública de debate entre agricultores familiares e o estado? In: Organizações Rurais \& Agroindustriais, Lavras, v. 9, n. 2, p. 241-255, 2007. 
MUCCI, C. B. M. R. e. \& MAFRA, R. L. M. "Tá achando que aqui só tem bobim da roça?": Meios de vida e participação de sujeitos rurais na elaboração de um plano municipal de desenvolvimento rural sustentável. In: Por Extenso: Boletim de Pesquisas do Programa de Pós Graduação em Extensão Rural, n 7, 2015.

MUCCI, C. B. M. R. e. e MAFRA, R. L. M. Pesquisa-ação e mediação dialógica como práticas metodológicas para emergência da ação comunicativa em Conselhos Gestores de Políticas Públicas. In: Rev. Adm. Pública - Rio de Janeiro 50(1):107-128, jan./fev. 2016.

NICOLETTI, André S. \& PINTO, Céli R. J. Democracia Radical: uma discussão teórica acerca das contribuições e limitações dessa teoria no cenário da teoria democrática contemporânea. In: XIII Enpos - Encontro de Pós-Graduação, 2011.

OLIVEIRA, Vanessa V. de. Desafios para o avanço dos direitos humanos no Brasil: uma análise das justificações no debate mediado em torno do caso do PNDH-3. In: Revista Compolítica, n. 4, vol. 2, ed. agostodezembro, ano 2014. Rio de Janeiro: Compolítica, 2014.

OlIVAL, A. de A.; SPEXOTO, A. A. e RODRIGUES, J. A. Participação e cultura política: os conselhos municipais de desenvolvimento rural sustentável no território Portal da Amazônia. In: RER, Rio de Janeiro, vol. 45, $\mathrm{n}^{\circ}$ 04, p. 1013-1035, out/dez 2007 - Impressa em novembro 2007.

PREFEITURA MUNICIPAL DE VIÇOSA, PMV inicia inscrições para mecanização agrícola. Disponível em: $<$ http://www.vicosa.mg.gov.br/arquivos/imprensa/pmv-iniciainscricoes-para-mecanizacao-agricola $>$. Acesso em: 06 de dezembro de 2014.

RICHARDSON, Jarry R. \& colaboradores. Capítulo 13: Entrevista. In: Pesquisa Social: Métodos e Técnicas. $3^{a}$ edição, Editora Atlas. São Paulo, p. 207-219, 2007. 
SAMPAIO, Sergio B. de A. O olhar governamental sobre os conselhos de políticas públicas: o caso do conselho municipal de saúde de São Paulo no período de 2001 a 2004. Fundação Getúlio Vargas - EAESP. São Paulo. Fevereiro, 2006.

SANTOS, Boaventura. S. Para uma sociologia das ausências e uma sociologia das emergências. Revista Crítica de Ciências Sociais, n. 63, pp. 237-280, 2002.

SARAVIA, Enrique. Capítulo I: O conceito de política pública: Introdução à teoria da política pública. p. 21-42. In: Políticas públicas, Coletânea Volume 1. (Orgs.) SARAVIA, Enrique. \& FERRAREZI, Elisabete. ENAP, 2006, Brasília.

SCHNEIDER, Sergio. CAZELLA, Ademir, A. \& MATTEI, Lauro. Histórico, caracterização e dinâmica do Pronaf - Programa Nacional de Fortalecimento da Agricultura Familiar (1995-2003). In: Políticas Públicas e Participação Social no Brasil Rural, p. 21-49. (Orgs.) SCHNEIDER, Sergio. SILVA, K. Marcelo. \& MARQUES, Paulo, E. M. Editora UFRGS, 2009.

SECCHI, Leonardo. Capítulo 1: Percebendo as Políticas Públicas. In: Políticas Públicas: Conceitos, esquemas de análise, casos práticos. $2^{\mathrm{a}}$ edição, São Paulo: Cengag E Learning, 2013.

Capítulo 6: Participação na construção de políticas. In: Políticas Públicas: Conceitos, esquemas de análise, casos práticos. $2^{\mathrm{a}}$ edição, São Paulo: Cengag E Learning, 2013.

SEVERO, D. O. e ROS, M. A. Da. A Participação no Controle Social do SUS: concepção do Movimento dos Trabalhadores Rurais Sem Terra. In: Saúde Soc. São Paulo, v.21, supl.1, p.177-184, 2012.

SILVA, Lilian L. da. AMORIM, Wellington L. Um balanço teórico sobre a teoria da democracia deliberativa: As críticas de Joshua Cohen a Jürgen Habermas. In: Revista Interdisciplinar Científica Aplicada. Blumenau, v.4, $\mathrm{n}^{\circ} 1$, p. 140-159, Sem I 2010. 
SOUZA, Celina. Políticas Públicas: uma revisão da literatura. In: Sociologia, Porto Alegre, ano $8 n^{\circ} 16$, p.20-45. Dezembro, 2006.

TATAGIBA, L. 2002. Os conselhos gestores e a democratização das políticas públicas no Brasil. In: DAGNINO, E. (org.). Sociedade civil e espaços públicos no Brasil. São Paulo: Paz e Terra.

- Conselhos gestores de políticas públicas e democracia participativa: aprofundando o debate. In: Revista Sociologia Política, $\mathrm{n}^{\circ}$ 25 Curitiba, Nov. 2005.

Submetido em 30/05/2016

Aprovado em 12/08/2016

Sobre os autores

Anna Cláudia Campos e Santos

Mestranda pelo Programa de Pós-Graduação em Extensão Rural na Universidade Federal de Viçosa.

E-mail: accamposesantos@gmail.com

\section{Rennan Lanna Martins Mafra}

Doutor em Comunicação Social pela Universidade Federal de Minas Gerais e professor do Curso de Comunicação Social da Universidade Federal de Viçosa.

E-mail: rennan.mafra@ufv.br 